\title{
PENGGUNAAN SALINITAS YANG BERBEDA TERHADAP SINTASAN IKAN GIRU (Amphiprion ocellaris)
}

\author{
Sri Sukari Agustina ${ }^{(1)}$ dan Derli ${ }^{(2)}$ \\ (1) Staf Pengajar Fakultas Perikanan UNISMUH Luwuk Kabupaten Banggai \\ Email : asrisukari@yahoo.com \\ (2) Alumni Fakultas Perikanan Universitas Muhammadiyah Luwuk
}

\begin{abstract}
Abstrak
Penelitian ini dilaksanakan pada bulan Mei-Juni 2012 dan bertujuan untuk mengkaji penggunaan salinitas yang berbeda terhadap sintasan ikan giru (Amphiprion ocellaris). Hewan uji yang digunakan yaitu ikan giru yang berukuran $5-7 \mathrm{~cm}$ dan diperoleh dari perairan Bajo Kecamatan Liang Kabupaten Banggai Kepulauan. Rancangan yang digunakan dalam penelitian ini yaitu Rancangan Acak Lengkap (RAL) dengan 3 perlakuan penggunaan salinitas yaitu perlakuan A (penggunaan salinitas $20 \mathrm{ppt}$ ), perlakuan B (penggunaan salinitas $25 \mathrm{ppt}$ ) dan perlakuan $\mathrm{C}$ (penggunaan salinitas $30 \mathrm{ppt}$ ) dan masing-masing perlakuan terdiri dari 3 ulangan. Parameter yang diamati selama penelitian yaitu sintasan ikan giru, untuk mengetahui pengaruh penggunaan salinitas terhadap sintasan ikan giru, data yang diperoleh dianalisis dengan menggunakan analisis sidik ragam, dan apabila terjadi perbedaan yang nyata dilanjutkan dengan uji Beda Nyata Terkecil (BNT). Hasil penelitian menunjukkan bahwa penggunaan salinitas yang berbeda tidak memberikan pengaruh yang nyata terhadap sintasan ikan giru, dan kualitas air pada media pemeliharaan selama penelitian masih berada pada kisaran yang layak untuk kehidupan ikan giru dimana suhu berkisar antara $26-28^{\circ} \mathrm{C}$ dan $\mathrm{pH} 7,5-8$.
\end{abstract}

Kata kunci: salinitas, sintasan, ikan giru

\section{PENDAHULUAN}

Ikan giru memiliki tubuh berwarna oranye/jingga dengan tiga belang/ban berwarna putih pada bagian kepala, badan dan pangkal ekornya. Ikan giru disebut sebagai common clownfish atau false-clown anemone fish dengan nama latin ikan Amphiprion ocellaris (Ahmad, 2009). Sebagai ikan hias air laut, ikan giru memiliki nilai jual yang tinggi karena keberadaan ikan giru sebagai ikan hias air laut sendiri saat ini tidak lagi sebagai hiburan atau hobi semata tetapi telah berkembang menjadi objek yang dimanfaatkan bagi kepentingan dunia pendidikan, penelitian, medis maupun keperluan konservasi alam dan termasuk biota yang dilindungi. Kekayaan ikan giru di Indonesia sebagai ikan hias, menyebabkan peluang Indonesia sebagai pengekspor komoditas ikan hias sangat terbuka lebar. Sementara pemenuhan pasar ikan giru sebagai ikan hias hampir sepenuhnya masih mengandalkan hasil tangkapan dari alam.

Upaya untuk membudidayakan ikan giru di darat telah dilakukan di panti-panti pembenihan (hatchery), akan tetapi kendala utama yang dihadapi saat ini adalah masih rendahnya tingkat kelangsungan hidup ikan giru hingga siap diekspor. Berbagai faktor penyebab menjadi kendala keberhasilan produksi dalam kegiatan budidaya ikan giru, salah satunya adalah ikan giru memiliki standar terhadap kondisi lingkungannya terutama pada kisaran salinitas. Salinitas media pemeliharaan pada budidaya ikan giru sangat berkaitan sekali dengan keberhasilan untuk meningkatkan produksi ikan giru, karena di alam ikan giru menjalani hidupnya pada salinitas yang cukup tinggi. 
Menurut Fuiman dan Higgs (1996) menyatakan bahwa umumnya salinitas untuk kehidupan ikan giru (A.ocellaris) dipertahankan pada salinitas pada 30-32 ppt. Selanjutnya Burgess (1990) menyatakan bahwa pemeliharaan ikan giru (clownfish) membutuhkan beberapa persyaratan di antaranya suasana nyaman sehingga perlu adanya tanaman hidup/koral, cahaya sedang dan salinitas yang sesuai dengan kehidupannya.

Tujuan penelitian ini adalah untuk mengkaji penggunaan salinitas yang berbeda terhadap sintasan ikan giru (Amphiprion ocellaris).

\section{METODE PENELITIAN}

Penelitian ini dilaksanakan dari bulan Mei sampai bulan Juni 2012 di Laboratorium Stasiun Karantina Ikan Bubung Kecamatan Luwuk Kabupaten Banggai Provinsi Sulawesi Tengah. Hewan uji yang digunakan yaitu ikan giru yang berukuran 5-7 cm dan diperoleh dari perairan Bajo Kecamatan Liang Kabupaten Banggai Kepulauan. Rancangan yang digunakan dalam penelitian ini yaitu Rancangan Acak Lengkap (RAL) dengan 3 perlakuan penggunaan salinitas yaitu perlakuan A (penggunaan salinitas $20 \mathrm{ppt}$ ), perlakuan B (penggunaan salinitas $25 \mathrm{ppt}$ ) dan perlakuan $\mathrm{C}$ (penggunaan salinitas $30 \mathrm{ppt}$ ) dan masing-masing perlakuan terdiri dari 3 ulangan.

Prosedur penelitian yaitu mengambil hewan uji dari perairan Bajo Kecamatan Liang, selanjutnya dilakukan pengangkutan ketempat penelitian dengan menggunakan styrefoam/box dan ikan tersebut disimpan di aquarium. Sebelum hewan uji diletakkan dalam wadah-wadah penelitian maka dilakukan aklimatisasi terhadap pakan dan salinitas yang berbeda sesuai dengan perlakuan penelitian. Menyiapkan wadah percobaan berupa 9 akuarium yang sudah dicuci dengan air tawar dan dibersihkan, berukuran 40 × 30 x $30 \mathrm{~cm}^{2}$ dengan volume air sebanyak 10 liter dan ketinggian air $10 \mathrm{~cm}$.

Untuk mendapatkan media perlakuan sesuai dengan salinitas yang diinginkan maka dilakukan teknik pengenceran dengan air tawar. Pengenceran dilakukan dengan berpedoman pada rumus yang digunakan Effendi (2003) sebagai berikut :

$\mathrm{V} 1 \times \mathrm{M} 1=\mathrm{V} 2 \times \mathrm{M} 2+\mathrm{V} 3 \times \mathrm{M} 3$

Keterangan:

$\mathrm{V} 1=$ Volume air pada salinitas yang diinginkan

M1 = Salinitas yang diinginkan

V2 = Volume air pada salinitas awal

M2 = Salinitas awal

V3 = Volume air pada salinitas yang ditambahkan

M3 = Salinitas air yang ditambahkan

Organisme uji yang digunakan dalam perlakuan diaklimatisasi dengan dipelihara di akuarium yang telah berisi air dengan salinitas 20 ppt, 25 ppt dan 30 ppt serta aklimatisasi dilakukan selama 3 hari di akuarium. 
Setelah organisme uji diadaptasikan pada media bersalinitas $20 \mathrm{ppt}, 25 \mathrm{ppt}$ dan 30 ppt kemudian dimasukan ke dalam akuarium dengan kepadatan sama yakni 5 ekor/10 liter. Penyiponan sisa pakan dan feses ikan dilakukan seperlunya yang diharapkan mampu menjaga kualitas air di dalam sistem resirkulasi. Pakan diberikan sebanyak 5\% dari bobot biomass, sedangkan frekuensi pemberian pakan dilakukan 3 kali sehari. Penelitian ini dilakukan selama 45 hari dan dilakukan pencatatan hasil yang diperoleh. Pengumpulan data diperoleh dari hasil pengamatan sintasan ikan giru yang dilakukan setiap hari, sedangkan pengukuran kualitas air yang meliputi $\mathrm{pH}$, suhu dan salinitas dilakukan setiap hari selama penelitian dengan frekuensi 3 kali sehari yaitu pagi pada pukul 07.00, siang pada pukul 13.00 dan sore pada pukul 17.00.

Parameter yang diamati selama penelitian yaitu sintasan ikan giru dengan menggunakan rumus Effendi (1979) :

$$
\mathrm{SR}=\frac{\mathrm{Nt}}{\mathrm{No}} \times 100 \%
$$

Keterangan :

SR = Survival Rate $(\%)$

$\mathrm{Nt}=$ Jumlah ikan pada akhir pemeliharaan (ekor)

No $=$ Jumlah ikan pada saat awal (ekor)

Untuk mengetahui pengaruh penggunaan salinitas terhadap sintasan ikan giru, data yang diperoleh dianalisis dengan menggunakan analisis sidik ragam, dan apabila terjadi perbedaan yang nyata dilanjutkan dengan uji Beda Nyata Terkecil (BNT) (Gasperz,1991).

\section{HASIL DAN PEMBAHASAN}

Berdasarkan hasil penelitian penggunaan salinitas yang berbeda terhadap sintasan ikan giru (Amphiprion ocellaris) selama penelitian didapatkan data rata-rata sintasan ikan yang tersaji pada Tabel 1 .

Tabel 1 . Rata-rata sintasan (SR) ikan giru dengan penggunaan salinitas yang berbeda selama penelitian

\begin{tabular}{c|c}
\hline Perlakuan & SR $(\%)$ \\
& $\overline{(X} \pm$ SD) \\
\hline A (salinitas 20 ppt) & $100 \pm 0^{\mathrm{a}}$ \\
B (salinitas 25 ppt) & $100 \pm 0^{\mathrm{a}}$ \\
C (salinitas 30 ppt) & $100 \pm 0^{\mathrm{a}}$ \\
\hline
\end{tabular}

Keterangan : ${ }^{a}$ Huruf yang sama pada kolom yang sama menyatakan tidak berbeda nyata pada taraf $\alpha<5 \%$.

Hasil analisis Tabel 1 menunjukkan bahwa perlakuan A (salinitas 20 ppt), perlakuan B (salinitas $25 \mathrm{ppt}$ ) dan perlakuan C memberikan nilai rata-rata sintasan yang 
sama $(100 \pm 0 \%)$, artinya bahwa sintasan pada masing-masing perlakuan tidak memberikan perbedaan yang nyata.

Berdasarkan hasil penelitian ikan giru masih dapat hidup 100\% pada salinitas 20 ppt, 25 ppt dan 30 ppt, hal ini karena sintasan ikan giru tidak dipengaruhi oleh efek osmotik pada berbagai salinitas media. Menurut Tissera (2010) ikan giru (A. ocellaris) termasuk organisme akuatik yang bersifat euryhaline, yaitu mampu beradaptasi pada media dengan rentang salinitas lebar. Selanjutnya Gunarso (1985) menyatakan bahwa ikan cenderung untuk memilih medium dengan kadar silinitas yang lebih sesuai dengan tekanan osmotik tubuhnya. Ikan mempunyai tekanan osmotik yang berbeda dengan lingkungannya, oleh karena itu ikan harus mencegah kelebihan dan kekurangan air, agar proses-proses biologi dalam tubuhnya dapat berlangsung dengan normal.

Pada organisme akuatik seperti ikan, terdapat beberapa organ yang berperan dalam proses pengaturan tekanan osmotik atau osmoregulasi agar proses fisiologis di dalam tubuhnya dapat berjalan dengan normal (Affandi, 2002). Hal ini sesuai dengan pendapat Fujaya (2004) yang menyatakan bahwa osmoregulasi pada hewan air adalah upaya hewan air untuk mengontrol keseimbangan air dan ion antara tubuh dan lingkungannya, atau suatu proses pengaturan tekanan osmose. Hal ini penting dilakukan oleh organisme perairan karena (1) harus terjadi keseimbangan antara substansi tubuh dan lingkungan, (2) membran sel yang permeabel merupakan tempat lewatnya beberapa substansi yang bergerak cepat, (3) adanya perbedaan tekanan osmose antara cairan tubuh dan lingkungan. Semakin jauh perbedaan tekanan osmose antara tubuh dan lingkungan, semakin banyak energi metabolisme yang dibutuhkan untuk melakukan osmoregulasi sebagai upaya adaptasi.

Pada salinitas $20 \mathrm{ppt}, 25 \mathrm{ppt}$ dan salinitas $30 \mathrm{ppt}$ ikan giru melakukan proses osmoregulasi dengan pola regulasi hipotonik atau hiperosmotik yaitu pengaturan secara aktif konsentrasi cairan tubuh yang lebih rendah dari konsentrasi media. Fujaya (2004) menyatakan bahwa osmoregulasi beberapa golongan ikan mempunyai tiga pola regulasi ion dan air yang perlu dilakukan oleh ikan yaitu (1) regulasi hipertonik atau hiperosmotik (pada ikan air tawar), (2) regulasi hipotonik atau hipoosmotik (pada ikan air laut) dan (3) regulasi isotonik atau isoosmotik (ikan-iakan yang hidup di muara sungai).

Di alam asalnya ikan giru bukan hanya hidup di tempat kedalaman puluhan meter akan tetapi ikan giru ada yang hidup pada kedalaman kurang lebih 2 meter dan dekat dengan muara sungai atau bahkan berada pada daerah estuari. Menurut Grouther (2004); Fautin dan Alen (2003) yang menyatakan bahwa ikan giru (A.ocellras) dapat ditemukan pada kedalaman 1-12 m. dan ikan giru (A. ocellaris) ini terdapat pada daerah tropis. Salinitas dalam skala massa larval ikan giru yang dibesarkan dalam tangki/tank tetap dirawat pada salinitas 24-26 ppt.

Ikan memiliki kisaran salinitas tertentu yang sesuai dengan habitatnya dan berbeda pada setiap habitat ikan lainnya. Salinitas air laut dipengaruhi oleh berbagai faktor seperti pola sirkulasi air, penguapan, curah hujan dan aliran sungai. Perairan dengan tingkat curah hujan tinggi dan dipengaruhi oleh aliran sungai memiliki salinitas 
yang rendah sedangkan perairan yang memiliki penguapan yang tinggi, salinitas perairan yang tinggi. Selain itu pola sirkulasi juga berperan dalam penyebaran salinitas di suatu perairan (Nybakken, 2004).

\section{Kualitas Air}

Berdasarkan hasil pengukuran kualitas air (Tabel 2), didapatkan kisaran kualitas air pada masing-masing perlakuan selama penelitian masih dalam kisaran yang layak untuk kehidupan ikan giru, dimana suhu $26-28^{\circ} \mathrm{C}$, dan $\mathrm{pH} 7,5-8$. Hal ini sesuai dengan pendapat Istianto (1993) bahwa kisaran suhu yang layak untuk pemeliharaan ikan giru (A. ocellaris) dan ikan hias air laut berkisar 20-29 ${ }^{\circ}$ C. Sedangkan menurut Tullock (1998) bahwa suhu yang baik untuk akuarium laut berkisar $24-27^{0}$ C. Selanjutnya Ahmad (2009) menyatakan bahwa air laut biasanya bersifat alkalis dengan $\mathrm{pH}$ lebih dari 7 karena banyak mengandung garam yang bersifat alkalis. Air yang banyak mengandung $\mathrm{CO}_{2}$ biasanya mempunyai $\mathrm{pH}$ lebih rendah dari 7 dan bersifat asam. Derajat keasaman $(\mathrm{pH})$ air sebasar 6,5-9,0 sangat memadai bagi budidaya ikan, sedangkan menurut Cust dan Cox (1978) bahwa $\mathrm{pH}$ yang optimal untuk pertumbuhan ikan giru (A. ocellaris) yaitu $\mathrm{pH} 7,2-8,3$ atau $\mathrm{pH} 8-8,3$

Tabel 2. Kisaran kualitas air masing-masing perlakuan selama penelitian

\begin{tabular}{ccc}
\hline \multirow{2}{*}{ Perlakuan } & \multicolumn{2}{c}{ Kualitas air } \\
\cline { 2 - 3 } & Suhu $\left({ }^{\circ} \mathrm{C}\right)$ & $\mathrm{pH}$ \\
\hline A & $26-28$ & $7,5-8$ \\
\hline B & $26-28$ & $7,5-8$ \\
\hline C & $26-28$ & $7,5-8$ \\
\hline
\end{tabular}

Sumber. Data primer diolah (2012)

\section{KESIMPULAN}

Berdasarkan hasil penelitian dapat diambil kesimpulan bahwa penggunaan salinitas yang berbeda tidak memberikan pengaruh yang nyata terhadap sintasan ikan giru, dan kualitas air pada media pemeliharaan selama penelitian masih berada pada kisaran yang layak untuk kehidupan ikan giru dimana suhu berkisar antara $26-28^{\circ} \mathrm{C}$ dan $\mathrm{pH}$ 7,5-8.

\section{DAFTAR PUSTAKA}

Affandi, Ridwan, Usman Muhammad. 2002. Fisiologi Hewan Air. Pekanbaru: Unri Pres.

Ahmad,T. 2009. Budidaya Bandeng Secara Intensif. Jakarta: Penebar Swadaya.

Cust, G. and G Cox, 1978. Tropical Akuarium Fishes Fresh Water And Marine Lamp. Light Publishing London.

Efendie, M.I.1979. Metode Biologi Perikanan.Yayasan Dewi Sri. Bogor.

Effendi, H. 2003. Telaah Kualitas Air Bagi Pengelola Sumberdaya Dan Lingkungan Perairan. Kanasius. Jakarta.

Fautin, D. G. Dan G.R. Allen. 2003. Clown Fish. Http://Www. O-Fish.Com. (Nopember 2004) 
Fuiman, La, Higgs Dm, 1996. Ontogeni, Pertumbuhan Dan Merekrutan Proses, Dalam: Chambers, Rc, Trippel, Ea (Editor), Awal Kehidupan Sejarah Dan Rekrutmen Pada Populasi Ikan. Chapman Dan Hall, London, Hal 225-250.

Fujaya, Yushinta. 2004. Fisiologi Ikan : Dasar Pengembangan Teknik Perikanan. Rineka Cipta. Jakarta.

Gaspersz, V., 1991. Metode Perancangan Percobaan. CV. Armico. Bandung.

Grouther Mc, M. 2004. Amphiprion Percula (Lacepe, 1802) Http://Www. Australianmuseum.Com.(Nopember 2004).

Gunarso, W. 1985. Tingkah Laku Ikan Dalam Hubungannya Dengan Alat, Metode Dan Teknik Penangkapan Ikan (Tidak Dipublikasikan). Fakultas Perikanan Institut Pertanian Bogor.

Istiyanto. S., 1993. Peranan Simbiosis Anemone Laut (Stichodactyla Gigantea) Dan Ikan Klon (Amphiprion Percula) Terhadap Pertumbuhan Dan Kelangsungan Hidupnya. Bogor. Thesis S2. Tidak Dipublikasikan.

Nybakken, J. W. And M. D. Bertness. 2004. Marine Biology: An Ecological Approach.

Tissera, K., 2010. Global trade in ornamental fishes. Souvenir Ornamentals Kerala-2010 Dept. of Fisheries Govt. of Kerala, pp. 35-38.

Tullock, J. H., 1998. Clownfishes And Sea Anemones. Barron's. Wireless Boulevard. 